\title{
MAIA, Claúdia; PUGA, Vera Lúcia (Org.). História das mulheres e do gênero em Minas Gerais. Ilha de Santa Catarina: Editora Mulheres, 2015. 552p.
}

ROSANA DE JESUS DOS SANTOS

Universidade Federal de Uberlândia (UFF)

Escrever a história das mulheres e do gênero ainda é uma tarefa ousada. Desde os anos 1980, o tema chega ao Brasil e se consolida como um campo definido de pesquisa para as/os historiadoras/es ganhando visibilidade, apesar de ainda sofrer restrições no interior das instituições acadêmicas. O número significativo de publicações revela gradativo fortalecimento desse campo, como atesta 0 crescimento das publicações de livros, artigos em revistas especializadas, teses, dissertações e simpósios temáticos versando sobre 0 tema. O que significa escrever uma história das mulheres e do gênero? A história se tornou o lugar a partir do qual o feminismo questionou o sujeito universal moderno (homem, branco, heterossexual e cristão), fazendo emergir uma vasta gama de sujeitos históricos em suas especificidades de gênero, étnico-raciais, sociais e sexuais.

O livro História das mulheres e do gênero em Minas Gerais, organizado por Cláudia Maia (UNIMONTES) e Vera Puga (UFU) resulta de uma parceria de longa data entre as organizadoras, que são pesquisadoras conceituadas e bastante atuantes nos simpósios sobre "História das mulheres e do gênero" na Associação Nacional de Professoras/es Universitários de História (ANPUH). Cláudia Maia é doutora em História pela Universidade de Brasília, na área de Estudos Feministas e de Gênero, e pós-doutora pela Universidade Nova de Lisboa. Atua como professora adjunta do Departamento de História e dos Programas de Pós-graduação em História e de Letras/Estudos Literários, da Universidade Estadual de Montes Claros. Vera Puga é doutora em História Social pela Universidade de São Paulo (USP), desde 1998, e atualmente faz parte de algumas comissões: do Instituto Nacional de Estudos e Pesquisas Educacionais Anísio Teixeira (ENADE- Formação Geral) e da Secretaria de Políticas para as Mulheres (Comitê Técnico-Institucional, questões de gênero). É professora Associada II da Universidade Federal de Uberlândia (UFU), onde atua no Programa de Mestrado e Doutorado em História Social, no Núcleo de Estudos de Gênero e Mulheres (NEGUEM) e na Revista Caderno Espaço Feminino, como editora. 
O livro em questão conta ainda com a participação de pesquisadoras/es de vários estados brasileiros que se debruçaram sobre diferentes momentos da história das mulheres em Minas Gerais, partindo de variados tipos de fontes e abordagens metodológicas. Foi publicado pela Editora Mulheres e financiado pela Fundação de Amparo à Pesquisa do Estado de Minas Gerais (Fapemig). Trata-se de uma coletânea de 552 páginas, organizada em quatro partes que indicam os múltiplos olhares sobre as mulheres mineiras: 1) transgressoras e insubmissas mineiras; 2) damas, donas do sertão; 3) saberes e fazeres femininos; 4) casamento e maternidade: mecanismos de um destino social.

A primeira parte da obra é constituída por textos que tratam das variadas ações de mulheres mineiras em diferentes temporalidades e espaços, para romper com as amarras das tradições patriarcais. Através da escrita sensível da pesquisadora Diva do Couto Muniz, conhecemos professoras mineiras cujo conjunto de ações "insubordinadas, indóceis e indisciplinadas" fincaram um marco de resistência ante o conjunto das estratégias elaboradas nas Minas oitocentistas, para circunscrevê-las a um ideal de mestra, recatada e submissa. Encontramos também as mulheres que ousaram contrariar regras "sagradas" e constituíram famílias com padres, mesmo estando sujeitas a sanções sociais, conforme divisou Vanda Praxedes. Mulheres mineiras livres ou escravizadas com suas práticas e estratégias em favor da abolição, como a escravizada Catarina que se destacou pela "astúcia empreendida em seus projetos de liberdade" (p.87), são desveladas por Fabiana Macena. A mineira Maria Lacerda de Moura, sua trajetória e escrita libertárias compõem o texto escrito por Cláudia Maia e Patrícia Lessa. Os três últimos textos discorrem sobre a escrita feminina: Maura Lopes Cançado e sua vida marcada pela insanidade e transgressão das normas de gênero, cuja obra Hospício é Deus foi discutida de forma densa por Márcia Custódio e Alex Fabiano Jardim. Contribuindo para visibilizar as mulheres negras e suas escritas, Constância Duarte nos presenteia com uma análise belíssima de parte da obra da escritora mineira Conceição Evaristo. Nos contos analisados, as personagens negras nos convidam a conhecer suas trajetórias, nas quais a intersecção entre gênero, etnia e classe se fazem presentes nas suas estratégias, vivências e resistências cotidianas. Fechando a primeira parte, conhecemos Márcia, prostituta de Pouso Alegre, cujas cartas são analisadas por Varlei do Couto a partir da noção foucaultiana de escrita de si. Vivendo e lutando num contexto em que as campanhas de moralização e higienização sociais têm como foco seu local de trabalho e residência, Márcia elabora táticas de resistência, enquanto troca correspondências com pessoas de sua estima, nas quais fala de si e de sua posição frente à sociedade em que vive.

Na segunda parte da obra, intitulada "Damas, donas do sertão", os olhares das/os pesquisadoras/es se voltam para as regiões consideradas mais distantes de Minas Gerais: os sertões longínquos, tradicionalmente considerados como espaços do desmando e poderio falocêntricos, agora são relidos sob novo viés. Assim, conhecemos por meio do texto de Gilberto Noronha as imagens contraditórias construídas sobre Joaquina de Pompéu e sua atuação no Oeste de Minas Gerais, entre os séculos XVIII e XIX. Em alguns discursos, ela é a mulher reta, recatada e justa; em outros, figura como "caudilho de saias" ou "sinhá Braba", colérica, descomedida sexualmente e cruel com seus 
subordinados. Dona Tiburtina de Andrade Alves é outra mulher cuja posição ativa suscitou inúmeras representações: seu envolvimento em episódio sangrento da política de Montes Claros, no início do século XX, foi lido e relido ao longo do tempo a partir de várias perspectivas, sendo ora louvada, ora criticada, conforme destacam as autoras Maria de Fátima Nascimento e Filomena Cordeiro Reis. Correndo mundo através da literatura, as personagens femininas de Guimarães Rosa, tão vivazes quanto os viventes de carne e osso, em suas ações destecem o tecido da tradição falocêntrica e conduzem os destinos por caminhos por elas mesmas traçados. Zidica, Rivília e "Dlena, aranha em jejum" apresentam possibilidades de "desarticular o estabelecido" e nos são apresentadas com sua astúcia, pela pena sutil de Telma Borges.

Os textos que compõem a terceira parte da obra, denominada "Saberes e fazeres femininos", têm em comum o cuidado das/o autoras/res em ouvir as próprias mulheres acerca de seus conhecimentos e práticas e das formas pelas quais atuaram em suas comunidades. As falas das narradoras são permeadas de satisfação em rememorar suas trajetórias de vida e, ao mesmo tempo, reiteram sentidos tradicionais sobre as atividades consideradas como apanágio feminino ou masculino. Através do texto de Lúcia Helena da Costa, acessamos as narrativas das parteiras do norte de Minas Gerais cujas práticas de partejar sofreram a interferência dos médicos no processo de medicalização da saúde das mulheres e dos recém-nascidos, a partir dos anos de 1950. No texto de Cairo Katrib e Fernanda Naves, nas memórias de mulheres congadeiras em Ituiutaba se entrelaçam trajetórias pessoais e a prática cultural do Congado. Durante muito tempo silenciadas pela tradição judaico-cristã, as vozes das mulheres que atuaram na fundação de Igrejas pentecostais no Norte de Minas Gerais são enfim ouvidas por meio da pesquisa de João Augusto dos Santos. A ligação entre os fazeres considerados como femininos ligados à cozinha e aos hábitos alimentares mineiros são discutidos por Mônica Abdala. Ainda sobre saberes, temos as narrativas das mulheres trabalhadoras rurais no Triângulo Mineiro, visibilizadas por Maria Andréa Angelotti. A exclusão feminina do acesso à educação formal é discutida por Leila Almeida, que se debruça sobre as narrativas de mulheres de Januária acerca de suas trajetórias de escolarização. As hierarquias de gênero que comumente estabelecem restrições diversas às mulheres marcaram a vida de muitas das narradoras, que foram impedidas de estudar durante a juventude por maridos ciumentos e obrigações domésticas. Encerrando a terceira parte, conhecemos a luta pela terra travada pelas mulheres negras remanescentes de um Quilombo em Paracatu, através da pesquisa de Maria Clara Machado e Paulo Sérgio da Silva.

O casamento e a maternidade têm sido apontados enfaticamente como formas de aprisionamento das mulheres, transformados em destinos social e biológico circunscrevendo as mulheres na esfera da casa e da família, submetidas a cerceamentos e violências. A quarta e última parte do livro se caracteriza por discutir os dispositivos sociais responsáveis por restringir as mulheres às funções de esposas e mães, bem como as estratégias encontradas por muitas para se livrarem de situações de violência em casamentos infelizes. Helen Ulhôa Pimentel examina documentação do século XVIII do tribunal eclesiástico instalado em Paracatu. A autora estuda o papel da Igreja quanto ao 
casamento e a possibilidade de anulação do mesmo. Entre a documentação encontrou vários casos nos quais as mulheres resistiram às imposições da Igreja e a procuravam buscando se livrar de situações intoleráveis, como casamentos violentos, o caso, por exemplo, de Joana de Souza Pereira. Na sequência, também tratando de casamento e divórcio, temos o texto de Dayse Lúcide Santos, que discute a legislação brasileira, do final do século XIX e início do século XX, acerca do tema e analisa alguns processos de separação ocorridos em Diamantina. Uma das conclusões a que chega é a de que havia um descompasso entre as normas instituídas pelo Estado e pela Igreja e as vivências de homens e mulheres, o que levava a transgressões da norma. Os discursos produzidos no início do século XX sobre os papéis das mulheres na formação dos cidadãos nas regiões do triângulo mineiro constituem foco da pesquisa de Florisvaldo Ribeiro Júnior. As mulheres eram "alvos de prescrições físicas e morais de jornalistas, médicos, intelectuais, políticos e padres", que procuravam estabelecer normas e controle sobre os seus corpos e condutas. Temos, aqui, excelente análise a respeito da relação entre as representações de gênero e os projetos de Nação Moderna do período. Na sequência, os discursos de mães adolescentes sobre maternidade e casamento, em Uberlândia, são analisados por Carla Denari, que percebe um descompasso entre os discursos do Estado acerca da gravidez na adolescência e os sentidos positivos que as mães adolescentes atribuem à maternidade e ao casamento. A educação enquanto espaço de produção das diferenças de gênero é objeto de Vera Lúcia Puga que percorre criticamente o processo educacional dicotômico, desde o século passado, com os internatos separados por sexo, até o presente, com a permanência da educação binária que se evidencia pelo funcionamento da escola de princesas em Uberlândia.

Enfim, o livro como um todo oferece uma importante contribuição para a história e os estudos de Gênero; seu diferencial é a abordagem centrada nas mulheres mineiras de várias regiões do estado, suas atuações em cada contexto onde se inseriram na luta pela liberdade de existir e agir. Se por um lado a obra congrega estudos variados que pretendem visibilizar as ações das mulheres mineiras, por outro tem nessa diversidade de perspectivas a emergência de alguns problemas: em alguns textos percebe-se que as mulheres estão subsumidas nas condições históricas de suas sociedades, em outros é possível vislumbrar a ideia de predestinação de determinadas mulheres para a atuação política em seus contextos. Notam-se também algumas lacunas no que tange às mulheres indígenas e às lesbianas, denotando uma ausência de estudos sobre essas mulheres em Minas Gerais e apontando, por outro lado, para a possibilidade de exploração destes campos pelas novas levas de historiadoras/es feministas. As brechas apontadas não diminuem o mérito da obra, visto que, nós historiadoras/es feministas somos conscientes de que todo texto histórico é parcial. Nesse sentido, as organizadoras na apresentação explicam que o "livro não teve a pretensão de percorrer o conjunto dos estudos que têm sido desenvolvidos sobre mulheres e gênero em Minas Gerais no 
campo da História, mas é uma pequena mostra desses estudos" ${ }^{11}$. Dentro do proposto, o livro contribui imensamente para que se conheça um pouco mais da história das mulheres mineiras.

\section{Sobre a autora}

Rosane de Jesus dos Santos é doutoranda em História na Universidade Federal de Uberlândia. Bolsista Fapemig. E-mail: mariabunitaxxi@yahoo.com.br.

Recebido em 03 de maio de 2015.

Aprovado em 10 de setembro de 2015.

\footnotetext{
${ }^{1}$ MAIA, Claúdia; PUGA, Vera Lúcia (Org.). História das mulheres e do gênero em Minas Gerais. Ilha de Santa Catarina: Editora Mulheres, 2015, p. 16.
} 